\title{
Opsætning af Web Feeds Atom/Rss
}


$\emptyset$ nsker man at tilvælge Web Feeds Atom/RSS skal man logge sig ind som Tidsskriftschef/Journal Manager og på startsiden vælge linket 'System-plug-ins'.

\section{Test 2}

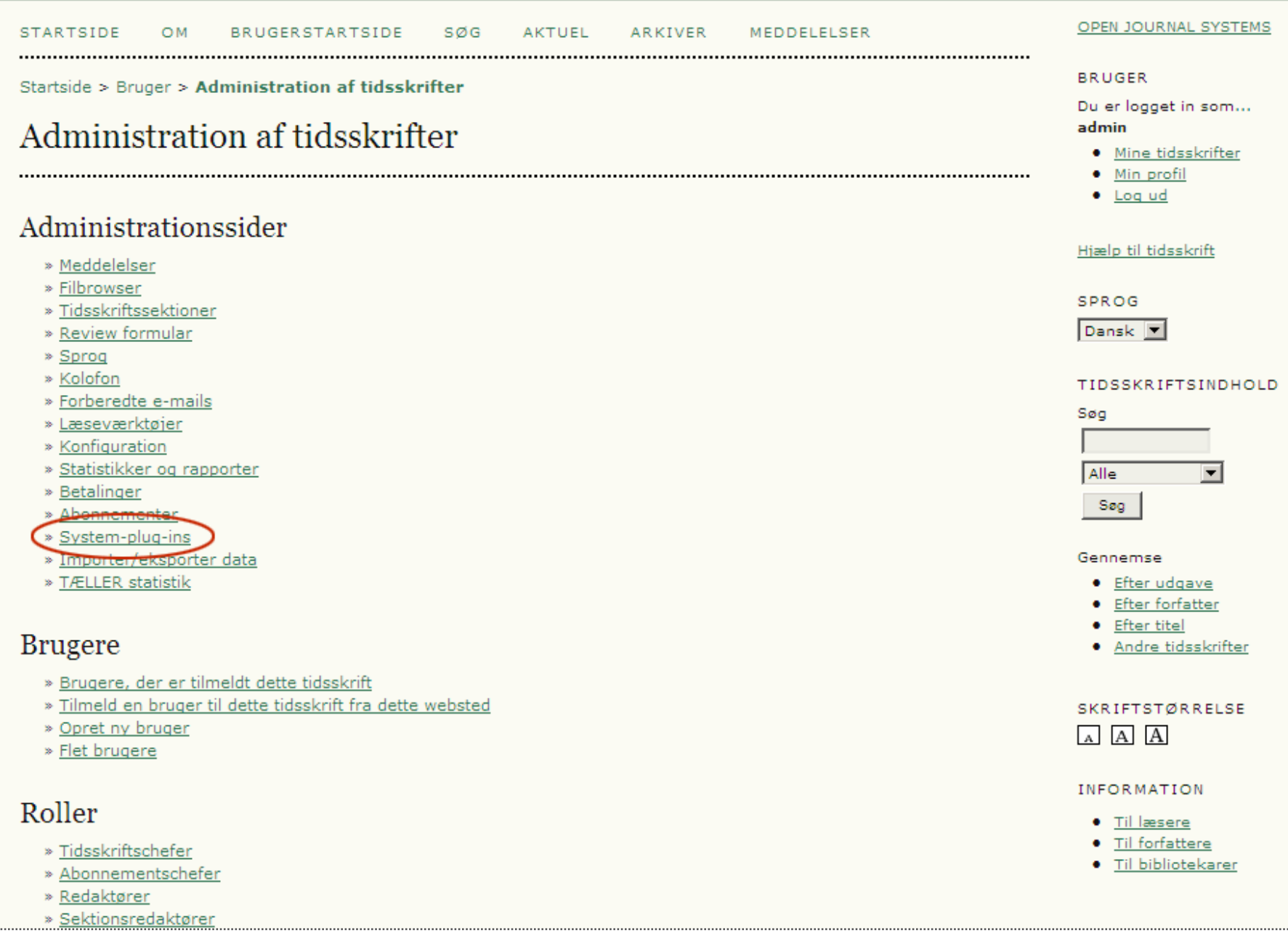




\section{På den fremkomne side finder man under 'Generiske plug-ins', Web Feed Plugin. For at tilvælge denne klikker man på linket 'AKTIVER'}

\section{Generiske plug-ins}

Generiske plug-ins bruges til at udvide Open Journal Systems på en rakke forskellige måder, der ikke understottes af de andre plug-in-kategorier.

phpMyVisites Plugin

Integrer OJS med phpMyVisites, en gratis og open source web site trafik-analyse applikation. Kraver at phpMyVisites er installeret. Se phpMvVisites site for mere information.

AKTIVER

Web Feed Plugin

Dette plugin genererer RSS/Atom web syndication feeds til det aktuelle nummer.

AKTIVER

COins Plugin

COinS plugin tilfojer en OpenURL descriptor til artikelsider (abstract og HTML), som f.eks. kan bruges til at trakke information til citeringsværktojer.

AKTIVER

OpenAds Plugin

OpenAds plugin tillader, at dynamiske tilføjelser fra OpenAds ad server bliver indsat i OJS. Læs README filen i plugins/generic/openAds for information om at aktiverer dette plugin.

TinyMCE Plugin

Dette plugin aktiverer WYSIWYG redigering af OJS tekstfelter ved hjæelp af TinyMCE tekstbehandleren. DEAKTIVER 
Aktiver-linket bliver herefter til et Deaktiver-link og ved siden af fremkommer et nyt link, Indstillinger. Via dette kan man vælge, hvor web feeds skal indsættes (se næste side)

\section{Generiske plug-ins}

Generiske plug-ins bruges til at udvide Open Journal Systems på en række forskellige måder, der ikke understottes af de andre plug-in-kategorier.

phpMyVisites Plugin

Integrer OJS med phpMyVisites, en gratis og open source web site trafik-analyse applikation. Kraver at phpMyVisites er installeret. Se phpMyvisites site for mere information.

AKTIVER

Web Feed Plugin

Dette plugin genereter-RSS/Atom web syndication feeds til det aktuelle nummer.

DEAKTIVER INDSTILLINGER 


\section{Under indstillinger vælges hvor web feed links skal forekomme.}

\section{Test 2}

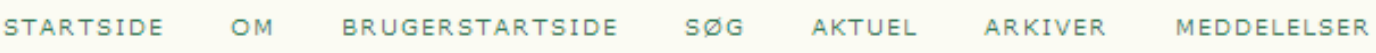

(6) Vis web feed links på alle sider i tidsskriftet.

C Vis kun web feed links på hjemmeside og sider for tidsskriftsnumre.

C Vis kun web feed links på sider for tidsskriftsnumre

c Vis artikler $\mathrm{i}$ det aktuelle nummer af tidsskriftet.

C $\square$ senest. publicerede artikler. 
Stadig som Tidsskriftschef/Journal Manager skal man til sidst gå ind under Konfiguration/Setup og derfra videre til Udseende/The Look.

Under 5.6 Tidsskriftslayout (1) markeres 'Web Feed Plugin' i midterfeltet (2) og for at få det placeret i højre margen klikkes på højreplinen (3). Husk at klikke på Gem-knappen nederst på siden.

Herefter vil læseren kunne abonnere på tidsskriftets web feed (4) og derved få besked, når et nyt nummer udkommer.
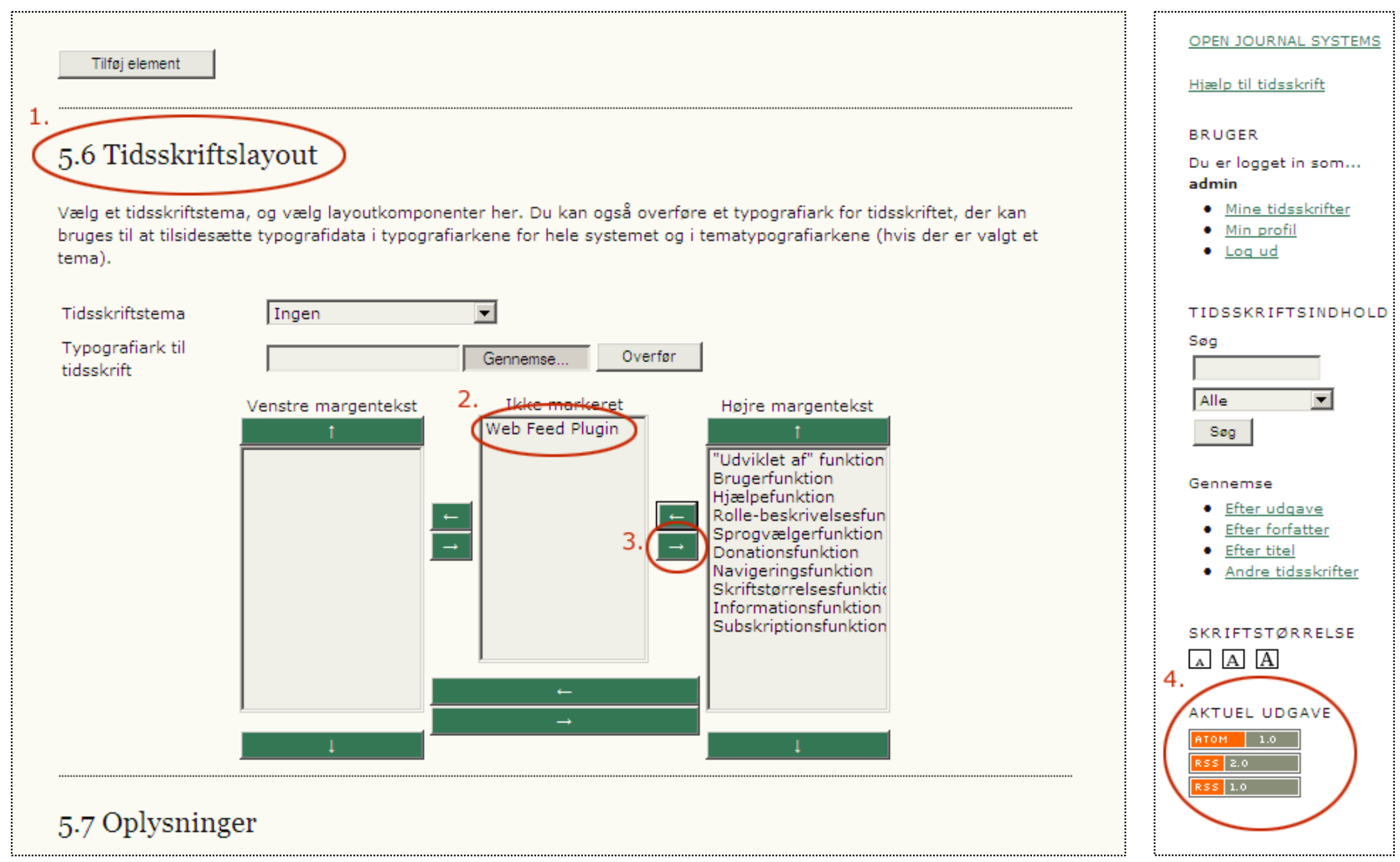